\title{
PENGETAHUAN DAN SIKAP TENAGA KESEHATAN TERHADAP PELAPORAN DAN SISTEM PELAPORAN MEDICATION ERROR DI RSU MONOMPIA GMIBM KOTA KOTAMOBAGU
}

\author{
Dwi Astuti Indah Baluntu ${ }^{1)}$, Weny I. Wiyono ${ }^{1)}$, Marina Mamarimbing ${ }^{1)}$ \\ ${ }^{1)}$ Program Studi Farmasi FMIPA UNSRAT Manado, 95115
}

\begin{abstract}
This research to determine the knowledge and attitudes of health workers regarding reporting and reporting systems of medication errors has been carried out. Medication errors is any event that can cause or resulted in improper health services or harm to patients that actually can be avoided. This research is a qualitative descriptive study using in-depth interviews with data analysis conducted using thematic analysis. The results showed that the health workers at Monompia General Hospital GMIBM Kotamobagu did not understand the reporting of medication errors, decision making to report medication errors was determined by the severity of the result of errors and lack of reporting due to fear of disciplinary action and fear of losing their jobs. Monompia General Hospital GMIBM Kotamobagu City continues to strive to improve the quality of health services, but the limitations of facilities and infrastructure as well as human resources were the obsracles.
\end{abstract}

Keywords : Knowledge, Medication Errors, Reporting System

\begin{abstract}
ABSTRAK
Telah dilakukan penelitian untuk mengetahui pengetahuan dan sikap tenaga kesehatan mengenai pelaporan dan sistem pelaporan medication error. Medication error merupakan setiap kejadian yang dapat menyebabkan atau berakibat pada pelayanan kesehatan yang tidak tepat atau membahayakan pasien yang sebenarnya dapat dihindari. Penelitian ini merupakan penelitian yang bersifat deskriptif kualitatif menggunakan wawancara mendalam dengan analisis data yang dilakukan menggunakan tematik analisis. Hasil penelitian menunjukan bahwa tenaga kesehatan di RSU Monompia GMIBM Kota Kotamobagu belum memahami mengenai pelaporan medication error, pengambilan keputusan untuk melaporkan kesalahan pengobatan ditentukan oleh tingkat keparahan hasil dari kesalahan dan minimnya tingkat pelaporan disebabkan karena tenaga kesehatan takut tindakan disiplin serta takut kehilangan pekerjaan. RSU Monompia GMIBM Kota Kotamobagu terus berupaya untuk meningkatkan mutu pelayanan kesehatan, tetapi keterbatasan sarana dan prasarana serta sumber daya manusia menjadi kendala tesendiri.
\end{abstract}

Kata kunci : Pengetahuan, Medication error, sistem pelaporan 


\section{PENDAHULUAN}

Menurut Depkes RI (2008), Keselamatan pasien (patient safety) rumah sakit adalah suatu sistem dimana rumah sakit membuat asuhan pasien lebih aman.

Pelaporan di rumah sakit dilakukan sesuai dengan Panduan Nasional Keselamatan Pasien Rumah Sakit (Patient Safety) dan Pedoman Pelaporan Insiden Keselamatan Pasien yang dikeluarkan oleh Komite Keselamatan Pasien Rumah Sakit - Persatuan Rumah Sakit Seluruh Indonesia (PERSI). Tujuan dilakukan pelaporan Insiden Keselamatan Pasien adalah untuk menurunkan Insiden Keselamatan Pasien yang terkait dengan KTD, KNC dan Kejadian Sentinel serta meningkatkan mutu pelayanan dan keselamatan pasien setiap kejadian dengan menggunakan formulir yang sudah disediakan di rumah sakit untuk diinvestigasi (KKPRS, 2015).

Studi lain yang dipublikasikan secara lokal tentang persepsi dokter dan apoteker terhadap pelaporan dan pencegahan medication error di klinik rawat jalan menunjukkan bahwa kedua profesi itu merasa bahwa menyalahkan individu merupakan penghalang untuk melaporkan tetapi bukan beban kerja yang berat. Tingkat pelaporan yang rendah memerlukan penyelidikan lebih lanjut tentang mengapa pelaporan tidak terjadi di antara HCP dalam pengaturan perawatan primer (Samsiah, 2016).

Berdasarkan latar belakang tersebut, terlihat jelas bahwa tingkat kejadian medication error cukup banyak terjadi di rumah sakit akan tetapi untuk tingkat pelaporan medication error sangatlah rendah dan belum adanya penelitian mengenai sikap tenaga kesehatan mengenai pelaporan medication error di indonesia. Untuk itu, peneliti tertarik melakukan penelitian mengenai pengetahuan dan sikap terhadap pelaporan medication error. RSU Monompia GMIBM Kota Kotamobagu adalah salah satu rumah sakit yang dipilih sebagai tempat penelitian.

\section{METODE PENELITIAN}

Waktu dan Tempat Penelitian

Penelitian ini dilakukan di RSU Monompia GMIBM Kota Kotamobagu dan waktu penelitian dimulai pada bulan JanuariFebruari 2019

\section{Jenis Penelitian}

Penelitian ini merupakan jenis penelitian deskriptif kualitatif menggunakan wawancara mendalam dengan pengambilan data secara prospektif. Penelitian dilakukan untuk mengetahui pengetahuan dan sikap terhadap medication error di RSU Monompia GMIBM Kota Kotamobagu pada bulan JanuariFebruari 2019.

\section{Populasi dan Sampel}

Populasi dalam penelitian ini yaitu seluruh tenaga kesehatan di RSU Monompia GMIBM Kota Kotamobagu. Sampel yang dijadikan subyek penelitian ini yaitu tenaga kesehatan yang terlibat dalam proses penulisan resep sampai obat diberikan kepada pasien di RSU Monompia GMIBM Kota Kotamobagu.

\section{Pengumpulan Data}

Penelitian ini menggunakan wawancara mendalam dimana sebuah surat resmi yang disertai dengan jadwal wawancara yang disarankan dikirim ke petugas kesehatan untuk meminta peserta dari berbagai latar belakang untuk berpartisipasi dalam wawancara. Wawancara dilakukan di ruangan tertutup 
selama jam kerja pada bulan Januari - Februari 2019. Sebelum wawancara, peserta diberi penjelasan tentang tujuan dan harapan penelitian. Selanjutnya, mereka menyelesaikan formulir persetujuan tertulis individual dan tabel data demografi. Wawancara direkam berdasarkan izin mereka dan panduan wawancara yang digunakan berdasarkan penelitian yang dilakukan Samsiah et al, (2016). Setiap wawancara memakan waktu 4560 menit dan dilakukan dalam bahasa Indonesia dan setiap peserta diberi nama samaran untuk tujuan kerahasiaan.

\section{Analisis Data}

Analisis data dilakukan secara thematic analysis dengan wawancara mendalam mengenai pengetahuan dan sikap tenaga kesehatan terhadap pelaporan medication error di RSU Monompia GMIBM Kota Kotamobagu.

\section{HASIL DAN PEMBAHASAN}

\section{HASIL}

Penelitian terkait pengetahuan dan sikap tenaga kesehatan terhadap pelaporan dan sistem pelaporan di RSU Monompia GMIBM Kota Kotamobagu, dilakukan terhadap 25 tenaga kesehatan dengan jumlah tahun pengalaman bekerja berkisar antara (4 Bulan - 39 Tahun) dengan metode pengambilan data secara convenience sempling, maka diperoleh data yang bervariasi dari masing-masing pasien. Hasil penelitian yang didapat dilakukan peer cheeking (Re-analisis data)

\section{Karakteristik Tenaga Kesehatan di RSU Monompia GMIBM Kota Kotamobagu}

Tabel1.Distribusi Karakteristik Tenaga Kesehatan $(n=25)$

\begin{tabular}{ccc}
\hline Karakteristik & \multicolumn{2}{c}{ Total } \\
\cline { 2 - 3 } Tenaga & $\mathbf{N}$ & $(\%)$ \\
Kesehatan & & \\
\hline Jenis Kelamin & & 48 \\
Laki-laki & 12 & 52 \\
Perempuan & 13 & \\
\hline *Usia (Tahun) & & 16 \\
17-25 Tahun & 4 & 56 \\
26-35 Tahun & 14 & 12 \\
36-45 Tahun & 3 & 4 \\
46-55 Tahun & 1 & 8 \\
56-65 Tahun & 2 & 4 \\
> 65 Tahun & 1 & \\
\hline Profesi & & 28 \\
Dokter & 7 & 56 \\
Perawat & 14 & 4 \\
Apoteker & 1 & 12 \\
Asisten & 3 & \\
\hline Masa Kerja & & 24 \\
< 1 Tahun & 6 & 48 \\
1-5 Tahun & 12 & 20 \\
6-10 Tahun & 2 & \\
> 11 Tahun & 5 & \\
\hline
\end{tabular}

Pengetahuan Tenaga Kesehatan Mengenai Medication Error di RSU Monompia GMIBM Kota Kotamobagu

Sebagian besar tenaga kesehatan mengatakan bahwa mereka mengetahui yang di maksud dengan medication error, akan tetapi saat diminta untuk menjelaskan mereka tidak bisa menjelaskan lebih mengenai Medication Error. Peryataan yang menunjukan hal tersebut antara lain :

"Kalau dari bahasa medication error itu berarti kesalahan pengobatan, hanya itu saja" (Perawat, wawancara 10)

"medication error mungkin kesalahan atau kelalaian di bidang medis yah"

(Dokter, Wawancara 23) 
Pengetahuan Tenaga Kesehatan Mengenai Sistem Pelaporan Medication Error di RSU Monompia GMIBM Kota Kotamobagu

Sebagian Tenaga Kesehatan tidak mengetahui ataupun belum cukup memahami mengenai pelaporan medication error yang menurut mereka hal tersebut diakibatkan karena tenaga yang kurang. Ketika diminta untuk menjelaskan sistem pelaporan medication error, ada juga yang menjawab dengan benar sedangkan beberapa tenaga kesehatan menjawab tidak tahu mengenai sistem pelaporan medication error. Pernyataan yang menunjukan hal tersebut antara lain:

"Sebenarnya, saya tidak tahu mengenai pelaporan ini" (Perawat, Wawancara 14)

"Selama inikan dirumah sakit belum terlalu jelas mengenai sistim ini jadi belum terlalu paham dan masih agak buta tentang hal ini.

(Dokter, Wawancara 21)

\section{Pengetahuan Tenaga Kesehatan Mengenai Keberadaan Sistem Pelaporan Medication Error Di RSU Monompia GMIBM Kota Kotamobagu}

Sebagian besar tenaga kesehatan menyatakan bahwa di rumah sakit tidak memiliki sistem pelaporan tetapi ada tenaga kesehatan yang menyatakan bahwa adanya sistem pelaporan tetapi belum ada sosialisasi yang baik. Pernyataan yang menyatakan hal tersebut antara lain :

"kalau untuk depe pelaporan ndak ada stau disini (Asisten apoteker, Wawancara 1)

"Untuk sistem pelaporan disini tidak ada dan untuk komite yang mengatur itu saja saya tidak tahu” (Perawat, wawancara 9)
"Sepertinya ada, karena belum disosialisasikan jadi kami yang bekerja dirumah sakit ini belum paham betul” (Dokter,Wawancara 21)

Beberapa tenaga kesehatan menggambarkan proses pelaporan jika terjadi kesalahan di rumah sakit, yaitu melapor kepada dokter atau ke kepala ruangan di rumah sakit dan sebagian lainnya masih terlihat bingung atau ragu dengan proses pelaporan di rumah sakit tempat mereka bekerja. Pernyataan yang menyatakan hal tersebut antara lain:

"Untuk pelaporan sendiri itu dilaporkan kepada kepala ruangan kemudian kepala ruangan melapor ke atasan kemudian dirapatkan bersama direktur dan ketua yayasan. Di dalam ruang rapat hanya kami bagian ruangan apotek dan direktur beserta ketua yayasan untuk membahasan medication error yang terjadi di dalam ruang lingkup apotek"

(Asisten apoteker, Wawancara 1)

"Biasanya disini kita melapor ke dokter penanggung jawab pasien (DPJD) akan tetapi kalaupun DPJP tidak mengangkat telfon biasanya kita langsung melaporkan ke dokter jaga di instalasi gawat darurat (IGD)." (Perawat, Wawancara 12)

\section{Sikap Tenaga Kesehatan Dalam Melaporkan Medication Error di RSU Monompia GMIBM Kota Kotamobagu}

Para tenaga kesehatan setuju bahwa keparahan hasil medication error merupakan faktor kunci yang mempengaruhi sikap untuk melaporkan kesalahan yang di lakukan sendiri atau rekan yang bersangkutan. Mereka mengatakan bahwa kedua kesalahan yang terjadi maupun yang hampir terjadi harus 
dilaporkan. Pernyataan yang menyatakan hal tersebut antara lain:

"Semua jenis kesalahan. Misalnya salah pemberian obat, salah pemberian jenis obat atau salah baca itu wajib dilaporkan. Walaupun kesalahan sekecil apapun harus dilaporkan"

(Dokter, Wawancara 18)

"kesalahan pemberian obat-obattan, baik penyediaannya,pemberiannya, penulisan resep) itu perlu dilaporkan supaya tahu kesalahan yang terjadi bagaimana dan seperti apa"

(Dokter, Wawancara 24)

Kebanyakan tenaga kesehatan menganggap kesalahan pengobatan yang melibatkan obat-obat untuk kondisi yang berat lebih cenderung dilaporkan dibandingkan dengan obat-obat untuk kondisi yang ringan, misalnya kesalahan yang berkaitan dengan suntik dan obat-obatan vaksinasi dianggap sangat penting untuk dilaporkan.

"Jenis medication error yang perlu dilaporkan ketika kita salah memberikan suntikan (injeksi intravena) kepada pasien dan efeknya pasien sampai kejang atau alergi dengan obat yang disuntikan menurut saya itu perlu dilaporkan" (Perawat, Wawancara 7)

"Kalau misalnya torang salah kase obat. Misalnya obat suntik, adakan obat-obat yang sama depe ampul? misalnya ondanserton deng apa begitu kita lupa...jadi menurut kita cuman kesalahan yang fatal yang tidak bisa diatasi yang perlu dilaporkan"

(Perawat, Wawancara 9)

"Misalnya pemberian injeksi, pemberian cairan IVFD (Intravenous fluids drip), pemberian dosis obat oral dan sebagainya" (Perawat, Wawancara 10)
Kesalahan yang dianggap ringan oleh tenaga kesehatan terutama yang melibatkan kesalahan resep seperti durasi pemberian yang salah, pemberian obat, salah membaca dan tertukar pasien tidak mungkin dilaporkan karena menurut mereka jenis kesalahan tersebut dapat diselesaikan melalui komunikasi ataupun pembinaan langsung dengan pasien atau di titik kesalahan terjadi. Pernyataan yang menyatakan hal tersebut antara lain :

"Misalnya salah pemberian resep pada pasien (tertukar nama), itu pernah terjadi disini tapi kita biasanya hanya melaporkan ke apotek bahwa mereka salah dalam pemberian resep, kalau untuk melaporkan kebagian manajemen itu belum pernah dilaporkan"

(Perawat, Wawancara 6)

"Saya melapor kalau hal itu sangat fatal, mempengaruhi citra rumah sakit, tapi kalau untuk kasus-kasus kecil mungkin kesalahan memberikan obat, kesalahan membaca itu biasanya kita tegur, pembinaan langsung.. Biasanya kita tidak memperluas sampai ketingkat manajeman tapi kalau dia melakukan hal tersebut berulang-ulang maka bisa diberikan suatu sanksi."

(Dokter, Wawancara 20)

"kalau saya tidak lapor biasanya itu saya yakin tidak akan terjadi apa-apa sih. Misalnya keliru ketorolac dengan analgetik yang lain, itu saya tidak terlalu bagaimana"

(Dokter, Wawancara 23)

Menurut tenaga kesehatan, kesalahan yang dilakukan oleh diri sendiri ataupun rekan kerja baik itu kesalahan yang tidak berbahaya yang tidak menghasilkan efek yang berbahaya atau yang belum sampai kepada pasien, maka mereka segera mengambil tindakan dan 
menurut mereka kejadian tersebut tidak perlu dilaporkan. Pernyataan yang menyatakan hal tersebut antara lain :

"Misalnya, obat tersebut belum sempat diberikan kepada pasien dan sudah diketahui bahwa obat tersebut salah, yah tidak perlu dilaporkan, kita langsung perbaiki”"

(Dokter, Wawancara 18)

"Selagi dalam pemberian obat masih aman bagi pasien, tidak memberikan efek yang berbahaya itu tidak dilaporkan" (Perawat, Wawancara 25)

\section{Hambatan Dalam Melaporkan Kejadian Medication Error di RSU Monompia GMIBM Kota Kotamobagu}

Menurut tenaga kesehatan, tidak tersedianya sistem pelaporan dan prosedur yang tidak jelas membuat pelaporan bahkan lebih sulit. Mereka menyatakan keprihatinan atas reaksi orang lain termasuk atasan mereka, teman dan pasien atau keluarga pasien. Para tenaga kesehatan menganggap bahwa mereka akan disalahkan dan dihukum oleh atasan jika mereka melaporkan kesalahan yang terjadi. Akibatnya mereka menjadi takut untuk melaporkan kejadian medication error. Namun, keprihatinan ini dianggap faktor kecil, dan tidak menghalangi sebagian dari mereka untuk melaporkan kesalahan karena keselamatan pasien tetap menjadi prioritas utama. Pernyataan yang menyatakan hal tersebut antara lain :

"Tidak melaporkan yah karena untuk alurnya sendiri saya kan tidak tahu bagaimana prosesnya" (Dokter, Wawancara 22)

"Saya mau melapor kemana? Sistemnya saja tidak ada" (Dokter, Wawancara 24)
"Yah, karena saya takut dimarahi, , takut di pecat nanti hilang pekerjaan"

(Perawat, Wawancara 9)

"Karena takut dan tidak tahu harus melapor kemana"(Perawat, Wawancara 10)

Beberapa tenaga kesehatan menunjukkan alasan lain untuk melaporkan medication error yaitu untuk mencegah terulangnya. Mereka tidak ingin kesalahan yang sama berulang. Pernyataan yang menyatakan hal tersebut antara lain :

"Karena, keselamatan pasien lebih diutamakan dari hal apapun, agar kesalahan tidak akan terjadi lagi" (Perawat, Wawancara 13)

"Yah untuk diperbaiki, agar kesalahan tidak berulang-ulang” (Dokter, Wawancara 24)

\section{Faktor yang Menyebabkan Terjadinya Medication Error di RSU Monompia GMIBM Kota Kotamobagu}

Tenaga kesehatan yang diwawancarai menekankan bahwa sebagian besar kesalahan yang terjadi diakibatkan waktu mereka difokuskan pada perawatan pasien. Dibebani dengan tekanan dari beban kerja yang berat dan kekurangan staf serta kurangnya komunikasi antar tenaga kesehatan. Pernyataan yang menyatakan hal tersebut antara lain :

"Biasanya kami disini yang jaga hanya 3 orang dan pasien yang datang cukup banyak dan pasien yang datang harus diperiksa pada jam tersebut bertabrakan dengan pasien yang akan diberikan suntikan. Jadi, biasanya kita memindahkan jam suntikkan pasien tersebut dan lebih mengutamakan pemeriksaan pasien yang datang dengan segala kondisi baik itu gawat atau tidak" (Perawat, Wawancara 7) 
"Yang pengting disini yah adalah komunikasi kalau komunikasi kurang misalnya pihak apotek takut untuk mengkonfirmasikan kepada dokter dan mereka berspekulasi obat ini yang dituliskan maka hal itu bisa mengakibatkan kejadian yang fatal" (Dokter, Wawancara 21)

\section{Perubahan Yang Dirasakan Dalam Pelaporan Medication Error di RSU Monompia GMIBM Kota Kotamobagu}

Peneliti menemukan bahwa perubahan yang tenaga kesehatan rasakan terhadap pelaporan medication error itu hanya sebatas pelaporan secara lisan kepada dokter sedangkan sebagian lainnya lagi menegaskan bahwa mereka tidak bisa melihat perubahan karena belum tersedianya sistem pelaporan. Pernyataan yang menyatakan hal tersebut antara lain :

"Yah karena belum adanya form medication error jadi saya belum tahu juga perubahannya seperti apa. Kalau berdasarkan ke kepala ruangan atau ke dokter itu dia pe tingkat ke error-an menjadi lebih kecil"

(Perawat, Wawancara 10)

"Karena dirumah sakit ini tidak ada pelaporan resmi, saya tidak bisa melihat perubahan apa yang terjadi. Dan karena ini kan perubahan yang terjadi berdasarkan kesalahan yang sudah dilaporkan sebenarnyakan harus ada monitoring dan disini saja belum ada pelaporan apalagi monitoring, kan habis pelaporan harus ada monitoring. Jadi, saya belum bisa melihat perubahan yang terjadi setelah adanya pelaporan" (Apoteker, Wawancara 3)

Sementara itu, beberapa tenaga mengatakan bahwa sistem pelaporan sangat perlu diadakan dan penting untuk rumah sakit karena menyangkut keselamat pasien dan dapat menjadi barang bukti bila terjadi kesalahan. Menurut tenaga kesehatan masih banyak yang harus di perbaiki di rumah sakit tempat mereka bekerja. Pernyataan yang menyatakan hal tersebut antara lain :

"Perlu yah, karena dapat menjadi bukti ataupun koreksi kalau misalnya terjadi kesalahan di rumah sakit ini"(Perawat, Wawancara 24)

"Perlu karena saya rasa penting yah. Tapi, untuk pertama kali tentunya kita harus memperbaiki faktor-faktor basic di rumah sakit"

(Dokter, wawancara 20)

\section{PEMBAHASAN}

\section{Karakteristik Tenaga Kesehatan di RSU Monompia GMIBM Kota Kotamobagu}

Karakteristik tenaga kesehatan berdasarkan jenis kelamin menunjukkan jumlah peserta laki-laki sebanyak 12 peserta (48\%) dan perempuan sebanyak 13 peserta (52\%). Hasil yang sama ditunjukkan penelitian sebelumnya yang dilakukan oleh Samsiah, et al (2016) yaitu dari total 31 tenaga kesehatan menunjukkan perempuan lebih banyak sebesar 18 Peserta $(58,06 \%)$ dan perempuan sebanyak 13 peserta $(41,94 \%)$.

Karakteristik usia pasien dikelompokkan berdasarkan Departemen Kesehatan RI (2009). Hasil penelitian terkait karakteristik usia menunjukkan bahwa yang paling banyak diwawancarai adalah pada kelompok usia 26-35 Tahun (Dewasa awal) sebanyak 14 peserta (56\%). Daya tangkap dan pola pikir seseorang terhadap suatu objek akan meningkat seiring dengan bertambahnya usia sehingga pengetahuan yang diperolehnya semakin membaik (Notoatmodjo, 2012). Akan 
tetapi pada penelitian ini didapatkan hasil bahwa faktor usia tidak berpengaruh terhadap tingkat pengetahuan tenaga kesehatan mengenai sistem pelaporan. Hal ini tidak menutup kemungkinan karena pengetahuan yang ia miliki bisa saja berasal dari pengetahuan yang dimilikinya sebelumnya, pengalaman pribadi maupun orang lain dan beberapa faktor lainnya yang dapat membentuk pengetahuan seseorang dalam jangka waktu yang lama dan akan bertahan sampai usia tua.

Berdasarkan hasil penelitian diperoleh data mayoritas tenaga kesehatan telah bekerja selama 1-5 tahun sebanyak 12 peserta (48\%) Menurut Mubarak, et al (2007) lingkungan pekerjaan dapat menjadikan seseorang memperoleh pengalaman dan pengetahuan baik secara langsung maupun tidak langsung.

\section{Pengetahuan Tenaga Kesehatan Mengenai Pelaporan Medication Error di RSU Monompia GMIBM Kota Kotamobagu}

Hasil penelitian ini menunjukkan sebagian besar tenaga kesehatan memahami medication error, akan tetapi tidak bisa menjelaskan lebih mengenai medication error. Mereka memahami medication error hanya berupa kesalahan pemberian obat yang tidak di instruksikan/tidak diresepkan. Sedangkan untuk pelaporan dan sistem pelaporan medication error, sebagian besar tenaga kesehatan belum memahami pelaporan medication error. Hal tersebut karena di RSU Monompia GMIBM Kota Kotamobagu menurut sebagian besar tenaga kesehatan tidak memiliki sistem pelaporan ataupun kurang sosialisasi dari pihak rumah sakit kepada mereka. Salah satu cara untuk mengatasi ini menurut Samsiah, et al (2016) adalah dengan membuat sistem pelaporan untuk medication error dan memasukkan pelaporan aktivitas kedalam alur kerja setiap tenaga kesehatan dan perlu diselenggarakan sosialisasi lebih banyak mengenai sistem pelaporan dan pelatihan tentang pelaporan medication error

Berdasarkan hasil penelitian di dapatkan proses pelaporan di rumah sakit jika terjadi kesalahan yaitu tenaga kesehatan melapor kepada dokter atau ke kapala ruangan di rumah sakit kemudian dokter ataupun kepala ruanganlah yang melapor ke pihak manajemen rumah sakit. Sedangkan menurut KKPRS (Komite Keselamatan Pasien Rumah Sakit) (2015), alur pelaporan insiden di rumah sakit dibagi menjadi 2 bagian yaitu alur Pelaporan insiden kepada tim keselamatan pasien di RS (Internal) dam alur Pelaporan insiden ke KKPRS - Komite Keselamatan Pasien Rumah Sakit (Eksternal).

\section{Sikap Tenaga Kesehatan Dalam Melaporkan Medication Error di RSU Monompia GMIBM Kota Kotamobagu}

Hasil Penelitian ini menujukkan bahwa semua tenaga kesehatan sadar akan pentingnya melaporkan medication error akan tetapi mereka juga menyadari bahwa tidak semua kejadian medication error harus dilaporkan karena banyaknya faktor yang terlibat, Menurut semua kategori tenaga kesehatan, tingkat keparahan dari hasil kesalahan pengobatan yang terjadi untuk pasien adalah pendorong utama untuk melaporkan medication error. Kesalahan yang berbahaya atau berpotensi berbahaya lebih mungkin dilaporkan daripada medication error yang dianggap tidak berbahaya. Hal tersebut dikarenakan menurut mereka kesalahan yang tidak membahayakan pasien atau tidak merugikan pasien masih bisa diatasi langsung, ataupun beberapa tenaga kesehatan khawatir atau takut tentang tindakan disiplin yang akan diberikan oleh atasan mereka 
sehingga mereka memilih untuk tidak melaporkan ke dokter ataupun ke bagian manajemen

Meskipun begitu, banyak peserta dalam penelitian ini memilih untuk melaporkan segala jenis kesalahan baik itu kesalahan yang sudah terjadi ataupun hampir terjadi. Hal tersebut karena menurut mereka dapat memberikan gambaran lengkap dari semua sumber risiko dan kejadian berbahaya bagi pasien serta keselamatan pasien adalah prioritas utama mereka. Sebagian peserta percaya bahwa pelaporan medication error harus menjadi tanggung jawab bersama dan harus di laporkan, hanya saja karena belum tersedianya sistem dan kurangnya pengetahuan tentang sistem pelaporan yang ada dan prosedur yang tepat juga merupakan hambatan untuk melaporkan medication error

\section{Hambatan Dalam Melaporkan Kejadian Medication Error di RSU Monompia GMIBM Kota Kotamobagu}

Pada penelitian ini didapatkan hasil bahwa tenaga kesehatan menyatakan keprihatinan atas reaksi orang lain termasuk atasan mereka, teman dan pasien atau keluarga mereka. Mereka percaya bahwa mereka akan disalahkan dan dihukum oleh atasan jika mereka melaporkan kesalahan yang terjadi. Akibatnya mereka menjadi takut untuk melaporkan kejadian medication error. Hasil penelitian ini sesuai dengan penelitian yang dilakukan oleh Osborne et al (1999), yang mendapatkan dari semua kejadian medication error hanya $25 \%$ yang dilaporkan menggunakan form insident reports. Laporan yang minim karena perawat menganggap pasien tidak dirugikan dalam situasi ini, selain itu perawat takut mendapatkan tindakan disiplin, takut kehilangan pekerjaan, takut diberi label perawat yang membuat kesalahan dan takut akan memburuknya reputasi unit

\section{Faktor Yang Menyebabkan Kejadian Medication Error di RSU Monompia GMIBM Kota Kotamobagu}

Hasil penelitian menyatakan tenaga kesehatan yang diwawancarai menekankan bahwa sebagian besar kesalahan yang terjadi diakibatkan oleh waktu mereka difokuskan pada perawatan pasien. Dibebani dengan tekanan dari beban kerja yang berat dan kekurangan staf serta kurangnya komunikasi antar tenaga kesehatan. Hasil penelitian ini sesuai dengan penelitian yang dilakukan oleh Wafiyahtunisa (2017), Faktor-faktor lain yang ikut berkontribusi pada kejadian Medication Error antara lain sebagai berikut : Komunikasi (mis-komunikasi, kegagalan dalam berkomunikasi), Kondisi Lingkungan, Gangguan atau interupsi pada saat bekerja, serta beban Kerja. Dan hasil penelitian ini sesuai juga dengan penelitian yang dilakukan oleh Samsial, A., Othman, N, et al (2016), bahwa bahwa mereka dibebani oleh tekanan dari beban kerja yang berat dan kekurangan staf, sehingga waktu untuk melaporkan kejadian medication error terbatas

\section{Perubahan Yang di Rasakan Dalam Pelaporan Medication Error di RSU Monompia GMIBM Kota Kotamobagu}

Pada penelitian ini didapatkan sebagian tenaga kesehatan tidak merasakan perubahan penting dalam proses pelaporan medication error hal tersebut mereka ungkapkan karena sistemnya dan alur pelaporannya belum jelas, jadi mereka belum bisa melihat perubahan dari pelaporan medication error. Menurut Samsiah, et al (2016), sejumlah perubahan penting dalam pelaporan medication error dapat digunakan 
sebagai ukuran dari sistem pelaporan yang sukses.

Semua tenaga kesehatan mengatakan bahwa sistem pelaporan medication error sangat penting dan perlu di suatu rumah sakit, menurut mereka dengan adanya pelaporan tersebut dapat mencegah terjadinya suatu kesalahan karna semua proses akan tercatat dan dapat digunakan sebagai barang bukti terjadinya kesalahan. Akan tetapi seorang dokter mengatakan, untuk pelaporan kesalahan medication error yang terjadi tergantung dari diri sendiri apakah mau melaporkan atau tidak, jujur atau tidak dalam proses pelaporan.

\section{KESIMPULAN}

Sebagian tenaga kesehatan di Rumah Sakit Umum Monompia GMIBM Kota Kotamobagu belum memahami mengenai pelaporan medication error akan tetapi mereka tahu bahwa pentingnya pelaporan medication error untuk meningkatkan keselamatan pasien dan untuk mencegah kesalahan terjadi. Pengambilan keputusan untuk melaporkan kesalahan pengobatan ditentukan oleh tingkat keparahan hasil dari kesalahan dan minimnya tingkat pelaporan disebabkan karena tenaga kesehatan takut tindakan disiplin serta takut kehilangan pekerjaan. Sebagian peserta setuju untuk melaporkan medication error jika mereka memahami sistem pelaporan kesalahan pengobatan seperti kapan harus melaporkan dan formulir yang harus digunakan serta tersedianya sistem pelaporan di rumah sakit.

\section{SARAN}

Membentuk sistem pelaporan untuk medication error dengan tujuan menurunkan angka kejadian KNC,KTD,KTC, Sentinel event dan memasukkan pelaporan aktivitas kedalam alur kerja setiap tenaga kesehatan dan perlu diselenggarakan sosialisasi lebih banyak mengenai sistem pelaporan dan pelatihan mengenai sistem pelaporan insiden mulai dari maksud, tujuan dan manfaat laporan, alur pelaporan, bagaimana cara mengisi formulir laporan insiden, kapan harus melaporkan, pengertian-pengertian yang digunakan dalam sistem pelaporan dan cara menganalisa laporan

\section{DAFTAR PUSTAKA}

Departemen Kesehatan Republik Indonesia. 2008. Panduan Nasional Keselamatan Pasien Rumah Sakit (Patient Safety): Utamakan Keselamatan Pasien. Depkes RI, Jakarta

Departemen Kesehatan Republik Indonesia. 2009. Penggolongan Usia. Ditjen Bina Kefarmasian dan Alat Kesehatan Depkes RI, Jakarta

Komite Keselamatan Pasien Rumah Sakit. 2015. Pedoman Pelaporan Insiden Keselamatan Pasien (IKP) (Patient Safety Incident Report). Jakarta

Samsiah, A., Othman, N, et al. 2016. Perseption and Attitudes Towards Medication Error Reporting In Primary Care Clinics: A Qualitative Study In Malaysia. Research Article Plos One. DOI:10.1371/journal.pone.0166114

Notoatmodjo, S. 2011. Metodologi Penelitian Kesehatan. Rineka Cipta, Jakarta

Notoatmodjo,S. 2012. Metodologi Penelitian Kesehatan. Jakarta: Rineka Cipta.

Mubarak, W.I., Chayatin N., Khoirul, I. R et al. 2007. Promosi Kesehatan Sebuah Pengantar Proses Belajar Mengajar 
Dalam Pendidikan. Graha Ilmu, Yogyakarta

Osborne, J \& Kathleen, B, et al. 1999. Nurses' Perceptions: When Is It a Medication Error?. The Journal of Nursing Administration 29(4) :33-38

Wafiyatunisa, Z. 2017. Kejadian Medication Error pada Fase Prescribing di Poliklinik Pasien Rawat Jalan RSD Mayjendhu Ryacudu Kotabumi [Skripsi]. Fakultas Kedokteran Universitas Lampung, Bandar Lampung 